\title{
Nanoscale
}

Check for updates

Cite this: Nanoscale, 2019, 11, 12242

\section{Real-time direct transmission electron microscopy imaging of phase and morphology transformation from solid indium oxide hydroxide to hollow corundum-type indium oxide nanocrystallites $\uparrow$}

\author{
Lukas Schlicker, (D)*a Radian Popescu, ${ }^{\mathrm{b}}$ Maged F. Bekheet, (D) ${ }^{a}$ Andrew Doran, (D) ${ }^{\mathrm{c}}$ \\ Dagmar Gerthsen ${ }^{\mathrm{b}}$ and Aleksander Gurlo (10 ${ }^{\text {a }}$
}

\begin{abstract}
A time-resolved series of high-resolution transmission electron microscopy (HRTEM) images are used to monitor phase and morphology transformation of rod-like and spherical particles with the initial orthorhombic InOOH phase in situ under continuous illumination with high-energy electrons in a transmission electron microscope. For both particle types, the electron-beam irradiation induces a fast $\mathrm{InOOH}$ to rh- $\mathrm{In}_{2} \mathrm{O}_{3}$ decomposition accompanied by the formation of voids within the particle/rod center. After illumination time intervals of about 1-2 min (i.e. electron dose 6.3-12.6 $\times 10^{7} \mathrm{e} \mathrm{nm}^{-2}$ ) for particles and $8 \mathrm{~min}\left(4.3 \times 10^{8} \mathrm{e} \mathrm{nm}^{-2}\right)$ for rods, respectively, several small empty cavities become visible in the particle/ rod center. The cavities coalesce and form a large hollow space/canal after further illumination. Timeresolved in situ HRTEM unambiguously shows that the formation of internal voids in both nanoparticle types is a consequence of the structural $\mathrm{InOOH}$-to-rh- $\mathrm{In}_{2} \mathrm{O}_{3}$ phase transition that starts at the surface of the corresponding particle. The as-formed oxide phase encapsulates the untransformed hydroxylated phase. Its decomposition does not follow the Kirkendall mechanism; the matter transferred outwards is removed in the form of water, leading to void formation inside without an increase of the particle size.
\end{abstract}

Received 11th March 2019, Accepted 31st May 2019

DOI: 10.1039/c9nr02115a rsc.li/nanoscale
High-resolution electron microscopy is one of the methods widely applied for studying single nanocrystals (see e.g. ref. 1, 2, 4 and 5) since it allows for direct imaging of their phase and shape evolution over time. An appearance of voids in metal oxides synthesized by the decomposition of the hydroxylated phases (oxyhydroxides, hydroxides) under a thermal treatment was previously reported for many systems; among them, the dehydroxylation of goethite to hematite, $\alpha-\mathrm{FeOOH}$ to $\alpha-\mathrm{Fe}_{2} \mathrm{O}_{3}$, and a diaspore to corundum, $\alpha-\mathrm{AOOH}$ to $\alpha-\mathrm{Al}_{2} \mathrm{O}_{3}$, are the most widely studied reactions, assessed directly in the microscope. For example, the in situ dehydroxylation of diaspore induced by an electron beam results in mesoporous transition alumina phases; ${ }^{11,12}$ goethite crystals transforms into a mosaic of highly oriented hematite crystallites ( $<5 \mathrm{~nm}$ across) separated by pairs of slit-shaped micropores ( $0.8 \mathrm{~nm}$ wide) running along the goethite needle axis which act as channels for water escape. ${ }^{13,14-16,17}$ In contrast to large crystals, i.e. slightly submicron-sized crystals, which disaggregate during thermal treatment/under electron (e)-beam irradiation, nanocrystals behave differently in several aspects. Paradoxically, the transformed oxide specimens retain the morphology of the starting materials and remain single crystals after the transformation, but with an internal void in the middle/center of the transformed spheres/rods.

\footnotetext{
${ }^{a}$ Fachgebiet Keramische Werkstoffe/Chair of Advanced Ceramic Materials, Institut für Werkstoffwissenschaften und -technologien, Technische Universität Berlin, Hardenbergstr. 40, D-10623 Berlin, Germany.E-mail: schlicker@tu-berlin.de ${ }^{b}$ Laboratorium für Elektronenmikroskopie, Karlsruher Institut für Technologie (KIT), Engesserstr. 7, D-76131 Karlsruhe, Germany

${ }^{c}$ Advanced Light Source, Lawrence Berkeley National Laboratory, Berkeley, California 94720, USA

$\dagger$ Electronic supplementary information (ESI) available. See DOI: 10.1039/ c9nr02115a
} 
In this context, our study provides an insight into the mechanism of these transformations clarifying controversial and paradoxical findings and underlines the complex interplay between phase and shape evolution. We take the decomposition of InOOH into corundum-type metastable rh- $\mathrm{In}_{2} \mathrm{O}_{3}$ as a model reaction to study the void formation in individual dense/solid single crystalline particles and rods. It allows also for a comparison to similar transformations in the aforementioned systems, revealing similarities to other corundum-type oxides, i.e. hematite and corundum itself, and for a desired synthesis of hollow nanostructures. The synthesis of hollow nanostructures has extensively been reviewed in the literature since 1998 when Caruso et al. reported a template-based synthesis approach for hollow silica spheres. ${ }^{18}$ Typically, the synthesis approaches towards hollow materials are differentiated between templating (i.e. hard, sacrificial and soft) and template-free methods. ${ }^{19,20}$ In our case, this transformation happens in situ in the electron microscope allowing for a desired manipulation of the material structure and morphology at the nanoscale.

\section{Results}

InOOH nanospheres are synthesized solvothermally as described in detail elsewhere; ${ }^{21}$ Fe-doped InOOH nanorods are obtained under the same conditions by adding to the starting solution iron(III) nitrate nonahydrate in the molar ratio In $: \mathrm{Fe}=95: 5$.

The X-ray diffraction (XRD) patterns (Fig. 1 panel $\mathrm{D}$ for ex situ and B + C for in situ characterization) confirm the orthorhombic InOOH phase $(P 21 \mathrm{~nm}$, no. $31, Z=2$ units of composition within the unit cell) in both specimens. The ex situ calcination of $\mathrm{InOOH}$ and Fe-doped InOOH samples in air for $30 \mathrm{~min}$ at $375^{\circ} \mathrm{C}$ and $450{ }^{\circ} \mathrm{C}$ leads to the phase-pure and irondoped metastable corundum-type $\operatorname{rh}-\operatorname{In}_{2} \mathrm{O}_{3}(R \overline{3} c$, no. $167, Z=$ 6 units of composition within the unit cell), respectively (Fig. 1A a-d shows HRTEM micrographs of all samples). This transformation was as well studied by time resolved in situ $\mathrm{XRD}{ }^{22}$ see Fig. $1 \mathrm{~B}$ and $\mathrm{C}$ for the contour plots of the InOOH to rh- $\mathrm{In}_{2} \mathrm{O}_{3}$ transformation (Fig. SI_3 in the ESI $\dagger$ shows the in situ contour plots in an enlarged format). The in situ XRD characterization reveals that the phase transformation from $\mathrm{InOOH}$ to rh- $\mathrm{In}_{2} \mathrm{O}_{3}$ proceeds directly without appearance of other intermediate crystalline structures. Energy dispersive X-ray spectroscopy (EDXS) analysis reveals the same $\mathrm{Fe}$ : In ratio of 0.03 in both Fe-doped $\mathrm{InOOH}$ and $\mathrm{rh}-\mathrm{In}_{2} \mathrm{O}_{3}$ materials, respectively. EDXS elemental maps based on the $\mathrm{In}-\mathrm{L}_{\alpha 1}, \mathrm{O}-\mathrm{K}_{\alpha}$ and $\mathrm{Fe}-\mathrm{K}_{\alpha 1} \mathrm{X}$-ray lines confirm uniform elemental distributions within particles before and after calcination (Fig. 2). No segregation of Fe-containing compounds is observed. Accordingly, in the following the iron-doped samples are denoted as $\mathrm{In}_{0.97} \mathrm{Fe}_{0.03} \mathrm{OOH}$ and $\mathrm{rh}-\mathrm{In}_{1.94} \mathrm{Fe}_{0.06} \mathrm{O}_{3}$. Single XRD line-profile analysis and Rietveld refinement of the XRD data reveal that $\mathrm{In}_{0.97} \mathrm{Fe}_{0.03} \mathrm{OOH}$ and $\mathrm{rh}-\mathrm{In}_{1.94} \mathrm{Fe}_{0.06} \mathrm{O}_{3}$ samples possess slightly smaller unit cell volumes in comparison with un-doped speci-
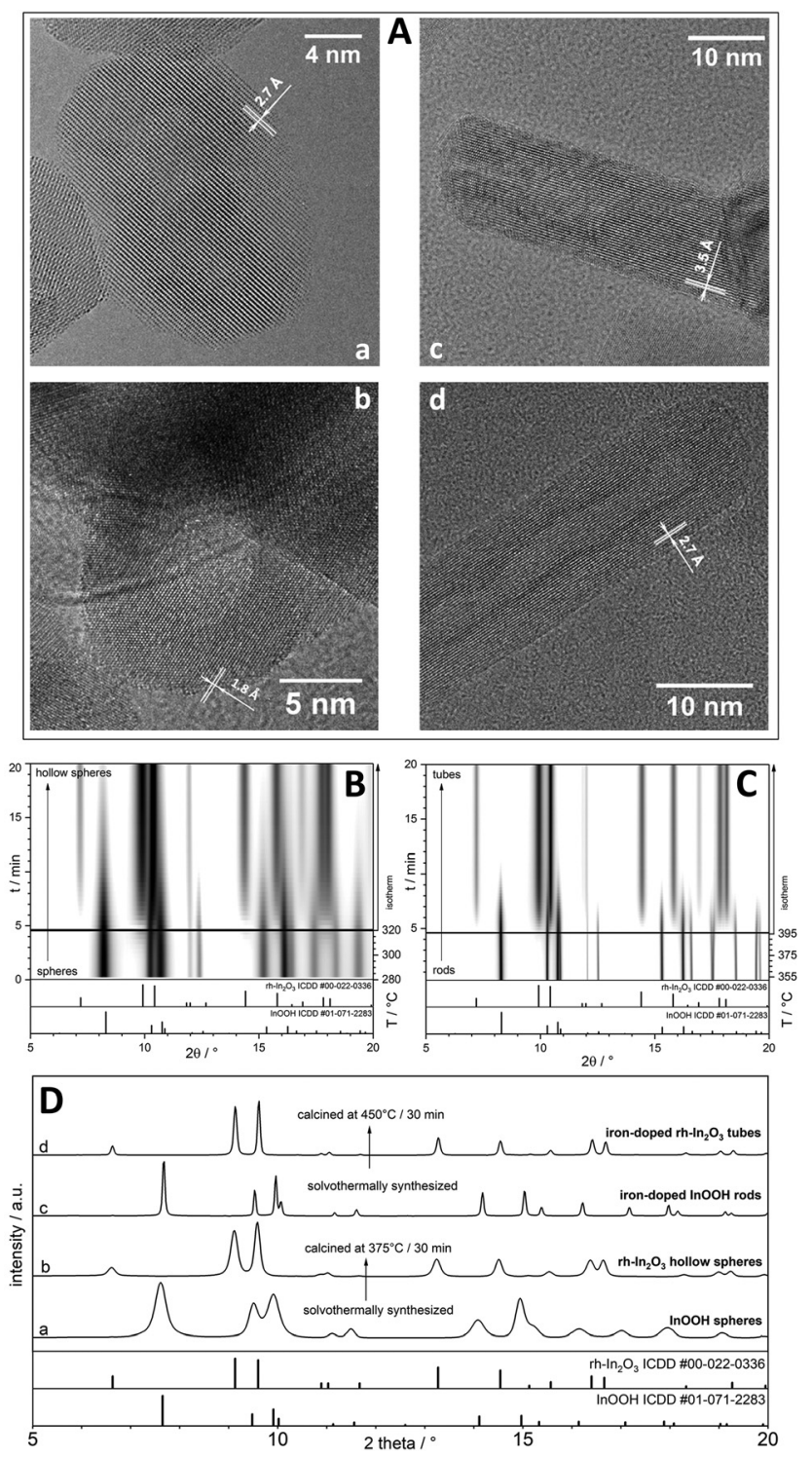

Fig. 1 (A) HRTEM micrographs of (a) InOOH spheres, (c) Fe-doped $\mathrm{InOOH}$ rods before calcination; (b) rh- $\ln _{2} \mathrm{O}_{3}$ hollow spheres and (d) Fedoped $\mathrm{rh}-\mathrm{In}_{2} \mathrm{O}_{3}$ tubes obtained upon calcination of the respective InOOH samples. (B) and (C): Time resolved in situ XRD contour plots of transformation during heating and isothermal holding of (B) $\operatorname{lnOOH}$ spheres to rh- $\ln _{2} \mathrm{O}_{3}$ hollow spheres at $320{ }^{\circ} \mathrm{C}$ and (C) of Fe-doped $\mathrm{InOOH}$ rods to $\mathrm{rh}-\mathrm{In}_{2} \mathrm{O}_{3}$ tubes at $395^{\circ} \mathrm{C}$. (D) XRD patterns of all four samples before and after ex situ calcination at $375^{\circ} \mathrm{C}$ and $450{ }^{\circ} \mathrm{C}$ respectively.

mens (Table 1). The decrease in the unit cell volume of Fedoped samples is due to the substitution of smaller $\mathrm{Fe}^{3+}$ for larger $\mathrm{In}^{3+}$ cations $\left[r\left(\mathrm{Fe}^{3+}\right.\right.$, high spin $)=64.5 \mathrm{pm}, r\left(\mathrm{In}^{3+}\right)=80$ pm; both ions are sixfold coordinated.$^{23}$

TEM reveals that InOOH and $\mathrm{In}_{0.97} \mathrm{Fe}_{0.03} \mathrm{OOH}$ samples consist of uniform dense sphere-like (Fig. 1a) and rod-like (Fig. 1c) nanoparticles, respectively. Both are single crystals as confirmed by continuous lattice fringes extending through the whole nanoparticles. Average fringe distances of $2.7 \pm 0.1 \AA$ and $3.5 \pm 0.1 \AA$ are observed in the InOOH nanospheres 

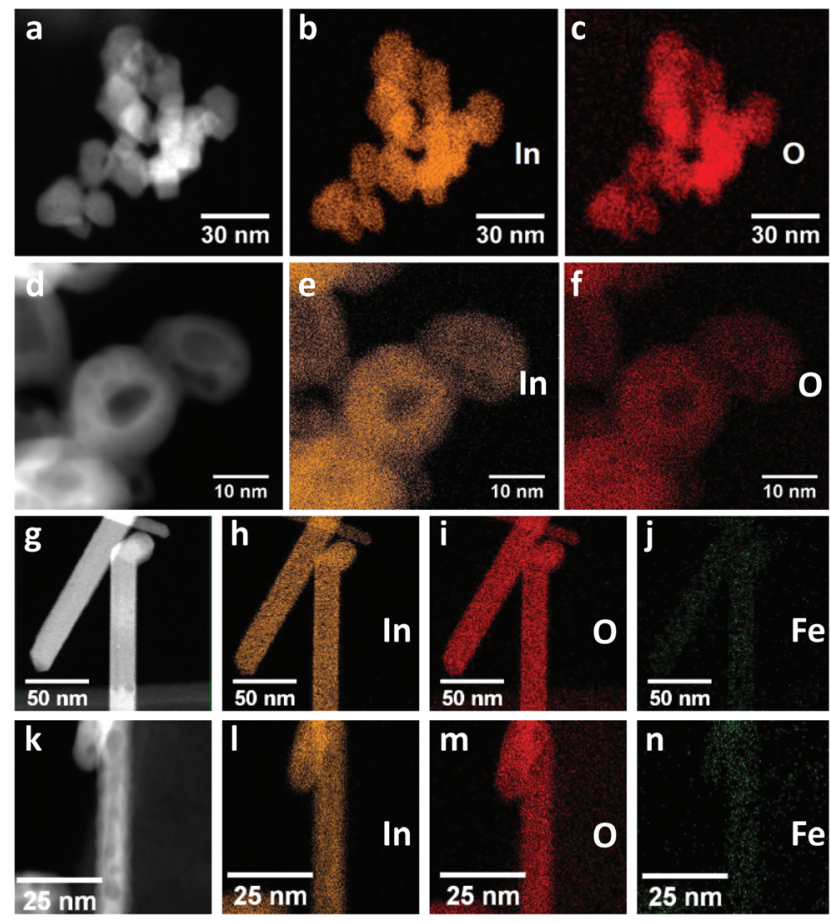

Fig. 2 (a-c) InOOH nanoparticles before and (d-f) hollow rh- $\ln _{2} \mathrm{O}_{3}$ nanoparticles after calcination. (a and d) High-angle annular dark-field field scanning transmission electron microscopy (HAADF-STEM) images and EDXS elemental maps of the $\mathrm{In}-\mathrm{L}_{\alpha 1}$ (orange, $\mathrm{b}$ and e) and $\mathrm{O}-\mathrm{K}_{\alpha}$ (red, $c$ and f) X-ray lines. ( $g-j) \mathrm{InOOH}$ nanorods before and $(k-n)$ rh$\mathrm{In}_{2} \mathrm{O}_{3}$ nanotubes after calcination. ( $\mathrm{g}$ and $\mathrm{k}$ ) HAADF STEM images and EDXS elemental maps of $\mathrm{In}-\mathrm{L}_{\alpha 1}$ (orange, $\mathrm{h}$ and $\mathrm{l}$ ), $\mathrm{O}-\mathrm{K}_{\alpha}$ (red, $\mathrm{i}$ and $\mathrm{m}$ ) and $\mathrm{Fe}-\mathrm{K}_{\alpha 1}$ (blue, $\mathrm{j}$ and $n$ ) $\mathrm{X}$-ray lines. The intensity of $\mathrm{X}$-ray lines indicates uniform elemental distributions within nanoparticles.

(Fig. 1a) and $\mathrm{In}_{0.97} \mathrm{Fe}_{0.03} \mathrm{OOH}$ nanorods (Fig. 1c), respectively, corresponding to the (011) and (110) plane distances in InOOH. ${ }^{24}$ The Fourier transform (FT) of the HRTEM images is in good agreement with calculated diffraction patterns of the orthorhombic InOOH structure (Fig. SI_1a,b and SI_2a,b $\dagger$ ) and confirms that the nanoparticles are mono-crystalline.

The most intriguing change induced by the annealing is found by a comparison of the starting material with the transformed specimens. Voids are formed in the transformed spheres (Fig. 1b) and tubes (Fig. 1d) which retain the mor- phology and size of the starting materials and remain single crystals after the transformation. A phase transformation into rh- $\mathrm{In}_{2} \mathrm{O}_{3}$ takes place which is verified by the agreement of the FT of the HRTEM images with calculated diffraction patterns of rh- $\mathrm{In}_{2} \mathrm{O}_{3}$ (Fig. SI_1c,d and SI_2c,d $\dagger$ ).

Average nanoparticle sizes are determined for each sample by fitting the lognormal distribution function ${ }^{25}$ to the experimental distribution derived by the TEM analysis of about 700 particles located on different HRTEM images (details are given in ESI and Fig. SI_4†). This yields an average diameter of $D_{\text {TEM }}=18 \pm 4 \mathrm{~nm}$ for the $\mathrm{InOOH}$ nanospheres. The same average outer diameter is measured for the hollow rh- $\operatorname{In}_{2} \mathrm{O}_{3}$ particles after transformation while their voids have an average size of $d_{\text {TEM }}=8 \pm 2 \mathrm{~nm}$. The average diameter of the $\mathrm{In}_{0.97} \mathrm{Fe}_{0.03} \mathrm{OOH}$ nanorods determined from their experimental distribution is $D_{\text {TEM }}=18 \pm 5 \mathrm{~nm}$, which also remains unchanged after transformation into tubes with an inner diameter $d_{\text {TEM }}$ of $8 \pm 3 \mathrm{~nm}$. All data including rod/tube lengths are compiled in Table 1.

The transition from solid to hollow particles is studied by a time-resolved series of HRTEM images recorded from the same nanoparticle to monitor the structure transformation in situ under continuous illumination with $300 \mathrm{keV}$ electrons in a transmission electron microscope. All microscope alignments are performed on sample regions, which are not considered for data collection. After moving the sample to the area of interest, refocusing is necessary, which takes approximately $20 \mathrm{~s}$.

The solid-to-hollow nanoparticle transition was investigated using an electron dose rate of $1.04 \times 10^{6} \mathrm{e} \mathrm{nm}^{-2} \mathrm{~s}^{-1}$ and a beam current of $9.7 \mathrm{nA}$ (Fig. 5). A slightly smaller dose rate of $0.89 \times 10^{6} \mathrm{e} \mathrm{nm}^{-2} \mathrm{~s}^{-1}$ and a beam current of $9.6 \mathrm{nA}$ were used for the nanorod-nanotube transition (Fig. 4). By illuminating a sample with electrons, energy will be transferred to the sample by inelastic scattering leading to a temperature rise. The temperature increase can only be calculated in a coarse approximation and is expected to amount to $\Delta T \approx 10{ }^{\circ} \mathrm{C}$ (nanorods) and $\Delta T \approx 12^{\circ} \mathrm{C}$ (nanoparticles) (for detailed calculations, see ESI $\dagger$ ). This indicates the minor role played by the temperature increase in the electron-beam induced phase and morphological transition of nanoparticles/nanorods, which will be shown in the following. The phase and morphological transitions

Table 1 Crystal structure parameters, average outer $(D)$ and inner $(d)$ diameters of the nanoparticles, and the length $(L)$ of the rods/tubes derived from XRD and TEM (details given in ESI)

\begin{tabular}{|c|c|c|c|c|c|c|}
\hline & InOOH [ref. 24] & rh- $\operatorname{In}_{2} \mathrm{O}_{3}$ [ref. 26] & InOOH spheres & rh- $\operatorname{In}_{2} \mathrm{O}_{3}$ hollow spheres & Fe-InOOH rods & rh-FeIn ${ }_{2} \mathrm{O}_{3}$ tubes \\
\hline$a[\AA]$ & 5.26 & 5.487 & $5.29 \pm 0.02$ & $5.49 \pm 0.01$ & $5.27 \pm 0.01$ & $5.48 \pm 0.01$ \\
\hline$b[\AA]$ & 4.56 & - & $4.57 \pm 0.02$ & - & $4.57 \pm 0.01$ & - \\
\hline$c[\AA]$ & 3.27 & 14.510 & $3.27 \pm 0.01$ & $14.51 \pm 0.01$ & $3.28 \pm 0.01$ & $14.50 \pm 0.01$ \\
\hline Vol cell $\left[\AA^{3}\right]$ & 78.43 & 378.33 & $79.05 \pm 0.52$ & $378.74 \pm 1.01$ & $79.00 \pm 0.33$ & $377.43 \pm 1.01$ \\
\hline$V / \operatorname{In}\left[\AA^{3}\right]$ & 39.22 & 31.53 & $39.53 \pm 0.26$ & $31.56 \pm 0.08$ & $39.50 \pm 0.16$ & $31.45 \pm 0.08$ \\
\hline$D_{\text {TEM }}[\mathrm{nm}]$ & & & $18 \pm 4$ & $18 \pm 4$ & $18 \pm 5$ & $18 \pm 5$ \\
\hline$d_{\mathrm{TEM}}[\mathrm{nm}]$ & & & - & $8 \pm 2$ & - & $8 \pm 3$ \\
\hline$D_{\mathrm{XRD}}[\mathrm{nm}]$ & & & $13 \pm 3$ & $14 \pm 4$ & - & - \\
\hline$d_{\mathrm{XRD}}[\mathrm{nm}]$ & & & & $8 \pm 2$ & & \\
\hline$L_{\text {TEM }}[\mathrm{nm}]$ & & & & & $30-576$ & $28-573$ \\
\hline
\end{tabular}


observed in situ in the transmission electron microscope are driven by knock-on processes due to elastic electron-atom collisions; also, breaking of bonds is involved. ${ }^{4}$ The observed transitions can therefore be described as an electron beam induced decomposition process, which is the combined result of knock-on and radiolysis. The average atom residence time on their sites is calculated to be between $22 \mathrm{~s}$ and $84 \mathrm{~s}$ (for details see ESI $\dagger$ ), which promotes reorganization of atoms during the phase transition and void formation.

The structural phase transition is further analyzed by calculating Fourier-filtered images. This requires to Fourier-transform the original HRTEM image. A Bragg reflection $(h k l)$ of the crystal structure of interest is then selected in the corresponding FT by using a circular aperture with a diameter equal to the half of the minimal distance up to its neighboring Bragg reflections. After artificial intensity enhancement of the selected reflection, an inverse FT is calculated by taking only the selected reflection into account (see $\mathrm{ESI}^{\dagger}$ for further details). The Fourier-filtered (FF) image reveals the size and location of regions with the crystal structure of interest and is used to selectively enhance the contrast of crystalline domains with either the orthorhombic InOOH or $\operatorname{rh}-\operatorname{In}_{2} \mathrm{O}_{3}$ phase. The procedure allows for a direct visualization of crystalline domains belonging to each of the two phases involved in the phase transition and the location of these regions on the nanoparticles. In Fig. 3 the intensity of the (120) reflection for InOOH $\left(d_{\left(\begin{array}{lll}-1 & 2 & 0\end{array}\right)}=2.09 \AA\right)$ and the $(20 \overline{4})$ reflection for rh- $\operatorname{In}_{2} \mathrm{O}_{3}$ $\left.\left(\begin{array}{lll}d_{(2} & 0 & -4\end{array}\right)=1.99 \AA\right)$ were selected and artificially increased by a factor of 20 to visualize the respective phases.

The tip of an $\mathrm{In}_{0.97} \mathrm{Fe}_{0.03} \mathrm{OOH}$ nanorod is displayed after $20 \mathrm{~s}$ illumination with the electron beam (electron dose $1.8 \times 10^{7}$ e $\mathrm{nm}^{-2}$ ) (Fig. 3) and after further illumination time intervals of 6, 18 and 30 min (Fig. 4). The $\mathrm{In}_{0.97} \mathrm{Fe}_{0.03} \mathrm{OOH}$ nanorod with a diameter of $23 \mathrm{~nm}$ does not contain any voids after $20 \mathrm{~s}$ electron illumination (Fig. 3a). The FT pattern of the rod tip in the HRTEM image in Fig. $3 \mathrm{~b}$ shows that the rod consists of two single-crystalline phases: (i) single-crystalline orthorhombic InOOH $(P 21 \mathrm{~nm}$, no. 31, with $a=5.26 \AA, b=4.56 \AA$ and $c=3.27 \AA$ ) in the [211]-zone axis (grey symbols and Miller indices) and (ii) single-crystalline $\mathrm{rh}-\mathrm{In}_{2} \mathrm{O}_{3}(R \overline{3} c$, no. 167, with $a=5.487 \AA, c=14.510 \AA$ ) in the [211]-zone axis (blue symbols and Miller indices). Considering the small Fe content of the rod/tube, which does not change the orthorhombic InOOH and rh- $\operatorname{In}_{2} \mathrm{O}_{3}$ structures, in the following we describe the rod/ tube compositions by omitting their Fe content. FT reveals that Bragg reflections of InOOH are sharp, characteristic of large and well crystallized regions with an $\mathrm{InOOH}$ structure, while the diffraction spots of $r$ - $\operatorname{In}_{2} \mathrm{O}_{3}$ are quite diffuse, indicating small and distorted regions with an $\mathrm{rh}-\mathrm{In}_{2} \mathrm{O}_{3}$ structure. The FF image obtained with the InOOH (120) reflection (Fig. 3c) shows that the (120) lattice fringes of the InOOH phase are aligned parallel to the rod axis, but the diameter of the rod region with the InOOH structure (Fig. 3c) is reduced to $19 \mathrm{~nm}$ compared to its initial value of $23 \mathrm{~nm}$ (Fig. 3a). The location of the rh- $\mathrm{In}_{2} \mathrm{O}_{3}$ structure can be deduced from the $\mathrm{FF}$ image obtained with the $(20 \overline{4})$ reflection, which visualizes the
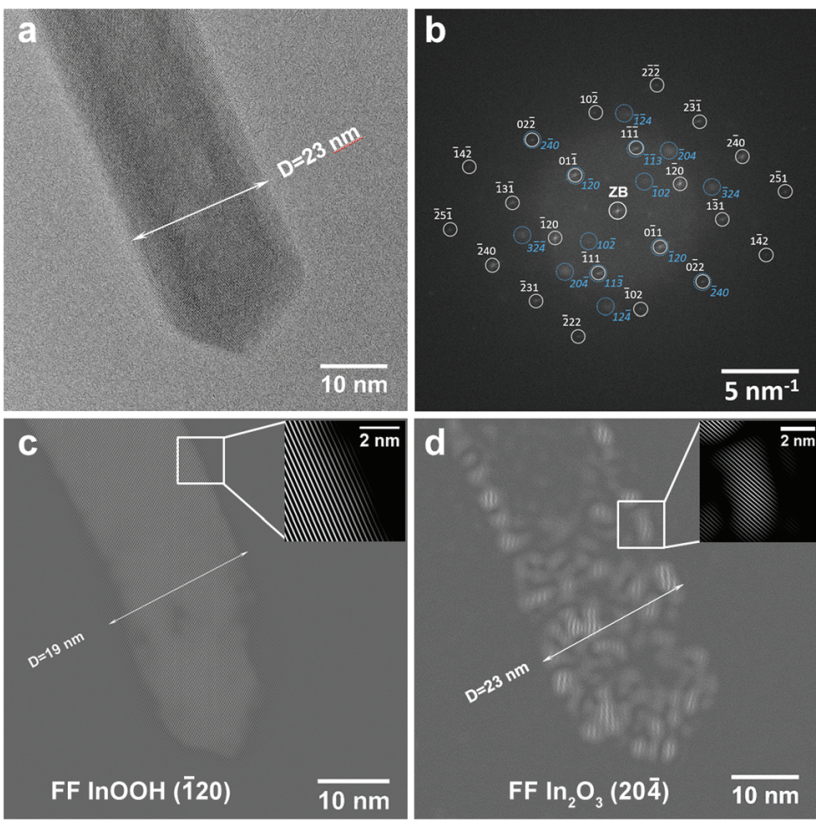

Fig. $3 \ln _{0.97} \mathrm{Fe}_{0.03} \mathrm{OOH}$ rod tip after $20 \mathrm{~s}$ illumination time with the 300 keV electrons: (a) HRTEM image, (b) FT of (a) showing that the rod is a mixture of the orthorhombic InOOH (gray circles and indices) and the rh- $\mathrm{In}_{2} \mathrm{O}_{3}$ (blue circles and indices) mono-crystalline phases, (c) FF image using the $\left(\begin{array}{lll}-1 & 2 & 0\end{array}\right)$ reflection of the $\mathrm{InOOH}$ structure. The inset shows lattice fringes with an average distance of $d=2.2 \AA$, corresponding to

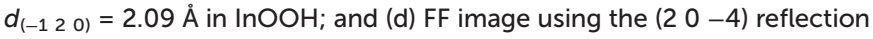
of the rh- $\ln _{2} \mathrm{O}_{3}$ structure. The inset shows lattice fringes with an average distance of $d=2.0 \AA$, corresponding to $d_{(20-4)}=1.99 \AA$ in $r h-\ln _{2} \mathrm{O}_{3}$.

$(20 \overline{4})$ planes of the rh- $\operatorname{In}_{2} \mathrm{O}_{3}$ structure (Fig. 3d). These fringes are located close to the rod surface. The rod has a diameter of $23 \mathrm{~nm}$ (Fig. 3d) in good agreement with the rod diameter on the HRTEM image (Fig. 3a). This indicates the formation of a $2 \mathrm{~nm}$ thin, single-crystalline $\mathrm{rh}-\mathrm{In}_{2} \mathrm{O}_{3}$ shell around the singlecrystalline InOOH core with a diameter of $19 \mathrm{~nm}$. We point out that, due to the projection of the surface over the core, on the $\mathrm{FF}_{(20 \overline{4})}$ image the shell region with the $\operatorname{In}_{2} \mathrm{O}_{3}$ structure is extended over the whole particle. Despite an apparent random distribution of rh- $\mathrm{In}_{2} \mathrm{O}_{3}$ regions at the rod surface, which indicates that the InOOH to $\mathrm{rh}-\mathrm{In}_{2} \mathrm{O}_{3}$ decomposition starts from multiple nucleation sites spread over the whole surface, all crystallites are well oriented with respect to each other resulting in a single-crystalline shell. Although TEM itself is not a surface sensitive method, the findings from the FF analysis of the rod tip discussed here suggest that the transformation from InOOH to rh- $\operatorname{In}_{2} \mathrm{O}_{3}$ starts at the surface of the rod. This demonstrates that only $20 \mathrm{~s}$ illumination time necessary to refocus and record the HRTEM image, i.e. an electron dose of $1.8 \times 10^{7}$ e nm${ }^{-2}$, is sufficient to initiate the $\mathrm{InOOH}$ to $\mathrm{rh}-\mathrm{In}_{2} \mathrm{O}_{3}$ phase transformation.

With increasing electron-beam irradiation up to $6 \mathrm{~min}$ and $20 \mathrm{~s}$, which corresponds to an electron dose of $3.4 \times 10^{8}$ e $\mathrm{nm}^{-2}$, the morphological rod-to-tube transformation begins to become visible on the corresponding HRTEM image (Fig. 4a), which shows the formation of non-connected voids 

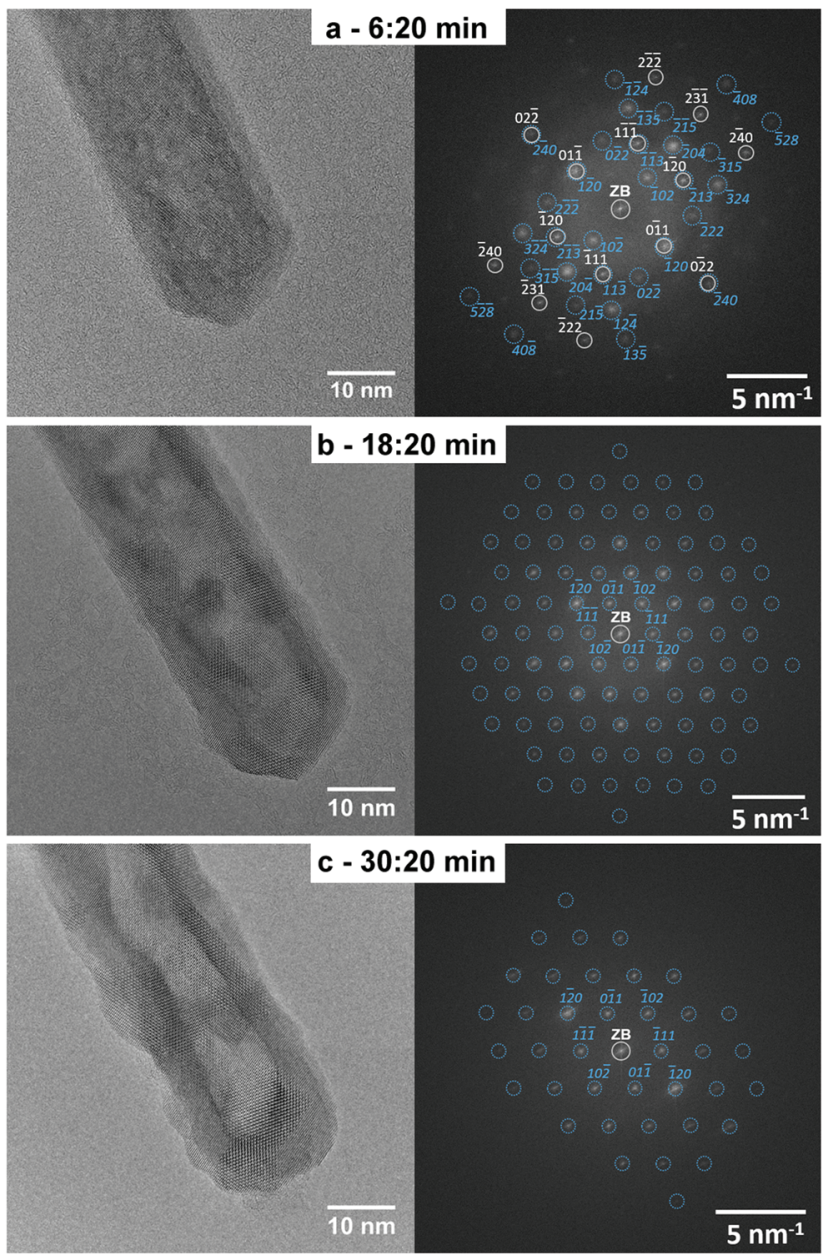

Fig. 4 HRTEM micrographs and corresponding FT images of the same $\mathrm{In}_{0.97} \mathrm{Fe}_{0.03} \mathrm{OOH}$ rod shown in Fig. 3 after further illumination with 300 $\mathrm{keV}$ electrons in a transmission electron microscope. (a) After 6 min and $20 \mathrm{~s}$, the rod consists of a mixture of the orthorhombic InOOH (space group $P 21 \mathrm{~nm}$, No. 31) and $\mathrm{rh}-\ln _{2} \mathrm{O}_{3}$ (space group $R \overline{3} \mathrm{C}$, No. 167) phases. This is demonstrated by the agreement of the FT of the HRTEM image with the calculated diffraction pattern of the orthorhombic InOOH structure in the [211]-zone axis (gray symbols and indices) and the calculated diffraction pattern of the rh- $-\mathrm{n}_{2} \mathrm{O}_{3}$ structure in the [211]-zone axis (blue symbols and indices). After (b) $18 \mathrm{~min}$ and $20 \mathrm{~s}$ and (c) $30 \mathrm{~min}$ and $20 \mathrm{~s}$ illumination, the whole rod is single-crystalline and consists of the rh- $\ln _{2} \mathrm{O}_{3}$ phase as demonstrated by the agreement between the FT images and calculated diffraction patterns of $r h-\ln _{2} \mathrm{O}_{3}$ in the [211]-zone axis. For legibility reasons, only a small number of reflections are marked and indexed in the FT shown in (b) and (c). The indices of all other reflections can be deduced from the low-index reflections.

in the rod core. The FT of the HRTEM image (Fig. 4a) indicates that $\mathrm{InOOH}$ and $\mathrm{rh}-\mathrm{In}_{2} \mathrm{O}_{3}$ are both still present as demonstrated by the agreement of their FTs with the calculated diffraction patterns of the two phases. Moreover, the FT reveals that the diffraction spots of the InOOH phase become more diffuse compared to the FT of the initial rod (Fig. 3b), but the peaks are still quite sharp, indicating the presence of relatively large, well crystallized InOOH regions in the rod core. In addition, the diffraction spots of the rh- $\operatorname{In}_{2} \mathrm{O}_{3}$ phase become sharper after further 6 min illumination as compared to those of the same phase after $20 \mathrm{~s}$ (Fig. 3b), indicating a higher degree of order and/or less strain. The FT in Fig. 4a also shows higher order Bragg reflections of the indium oxide phase compared to the FT of the initial rod (Fig. 3b). This indicates a better orientation of the rh- $\operatorname{In}_{2} \mathrm{O}_{3}$ shell in the [211]-zone axis, a decrease of its strain, and the increase of the monocrystalline shell (thickness) with the rh- $\operatorname{In}_{2} \mathrm{O}_{3}$ structure as compared with the $\mathrm{In}_{2} \mathrm{O}_{3}$ shell after $20 \mathrm{~s}$ illumination (Fig. 3b). However, the rh- $\mathrm{In}_{2} \mathrm{O}_{3}$ crystallites remain still small.

After $18 \mathrm{~min}$ and $20 \mathrm{~s}$ electron-beam illumination (corresponding electron dose $9.8 \times 10^{8} \mathrm{e} \mathrm{nm}^{-2}$ ), the $\mathrm{InOOH}-\mathrm{rh}-\mathrm{In}_{2} \mathrm{O}_{3}$ phase transition is completed. The whole rod in the HRTEM image in Fig. $4 \mathrm{~b}$ is a rh- $\operatorname{In}_{2} \mathrm{O}_{3}$ monocrystal, as indicated by the agreement between its FT and the calculated diffraction pattern. We emphasize that the rod remains single crystalline during the InOOH-rh- $\mathrm{In}_{2} \mathrm{O}_{3}$ phase transition. Moreover, the HRTEM image in Fig. 4b clearly reveals the morphological rodto-tube transition where an almost empty void is formed in the center of the rod. Prolonged illumination of $30 \mathrm{~min}$ and $20 \mathrm{~s}$ (corresponding electron dose $1.6 \times 10^{9} \mathrm{e} \mathrm{nm}^{-2}$ ) results in a complete rod-to-tube transition by the formation of an entirely empty canal in the middle of the rod observed by its bright contrast in the HRTEM image in Fig. 4c. The whole tube is a rh- $\mathrm{In}_{2} \mathrm{O}_{3}$ monocrystal as demonstrated by its indexed FT.

Our study demonstrates that monocrystalline $\mathrm{In}_{0.97} \mathrm{Fe}_{0.03} \mathrm{OOH}$ rods transform into monocrystalline rh- $\mathrm{In}_{1.94} \mathrm{Fe}_{0.06} \mathrm{O}_{3}$ tubes, which can be obtained either after long illumination of about $30 \mathrm{~min}$ by high-energy electrons in a transmission electron microscope (corresponding electron dose of $1.6 \times 10^{9} \mathrm{e} \mathrm{nm}^{-2}$ ) or after the ex situ annealing in a furnace at $450{ }^{\circ} \mathrm{C}$ for $30 \mathrm{~min}$.

The structural and morphological transformation from solid to hollow sphere-like nanoparticles occurs in the same way as the previously described rod-to-tube transformation. The phase transition proceeds quickly first, and the nanoparticles remain single-crystalline at any stage of the transformation. To illustrate the transformation process, Fig. 5 displays a time series of HRTEM images, which allows to monitor the transformation of a solid InOOH particle into a rh- $\mathrm{In}_{2} \mathrm{O}_{3}$ hollow particle induced by the illumination with $300 \mathrm{keV}$ electrons. The HRTEM image of the InOOH particle in Fig. 5a was taken after $20 \mathrm{~s}$ illumination time (electron dose of $2.1 \times 10^{7} \mathrm{e} \mathrm{nm}^{-2}$ ), necessary to refocus and record the HRTEM image. The FT of the HRTEM image (Fig. 5a) can be explained by the presence of monocrystalline $\mathrm{InOOH}$ in the [011]-zone axis (gray symbols and Miller indices) and monocrystalline rh$\mathrm{In}_{2} \mathrm{O}_{3}$ in the [211]-zone axis (blue symbols and Miller indices).

After $2 \mathrm{~min}$ and $20 \mathrm{~s}$ illumination with the electron beam (electron dose $1.5 \times 10^{8} \mathrm{e} \mathrm{nm}^{-2}$ ), the solid-to-hollow-particle transformation starts as indicated by the appearance of first voids (HRTEM image in Fig. 5b), while the InOOH-to-rh- $\operatorname{In}_{2} \mathrm{O}_{3}$ phase transition is already finished as demonstrated by the good agreement of its FT and the calculated diffraction pattern of rh$\mathrm{In}_{2} \mathrm{O}_{3}$ in the [211]-zone axis (Fig. 5b). Finally, a large void in the center of the nanoparticle is formed after $10 \mathrm{~min}$ and $20 \mathrm{~s}$ continuous illumination with an electron dose of $6.5 \times 10^{8} \mathrm{e} \mathrm{nm}^{-2}$ 

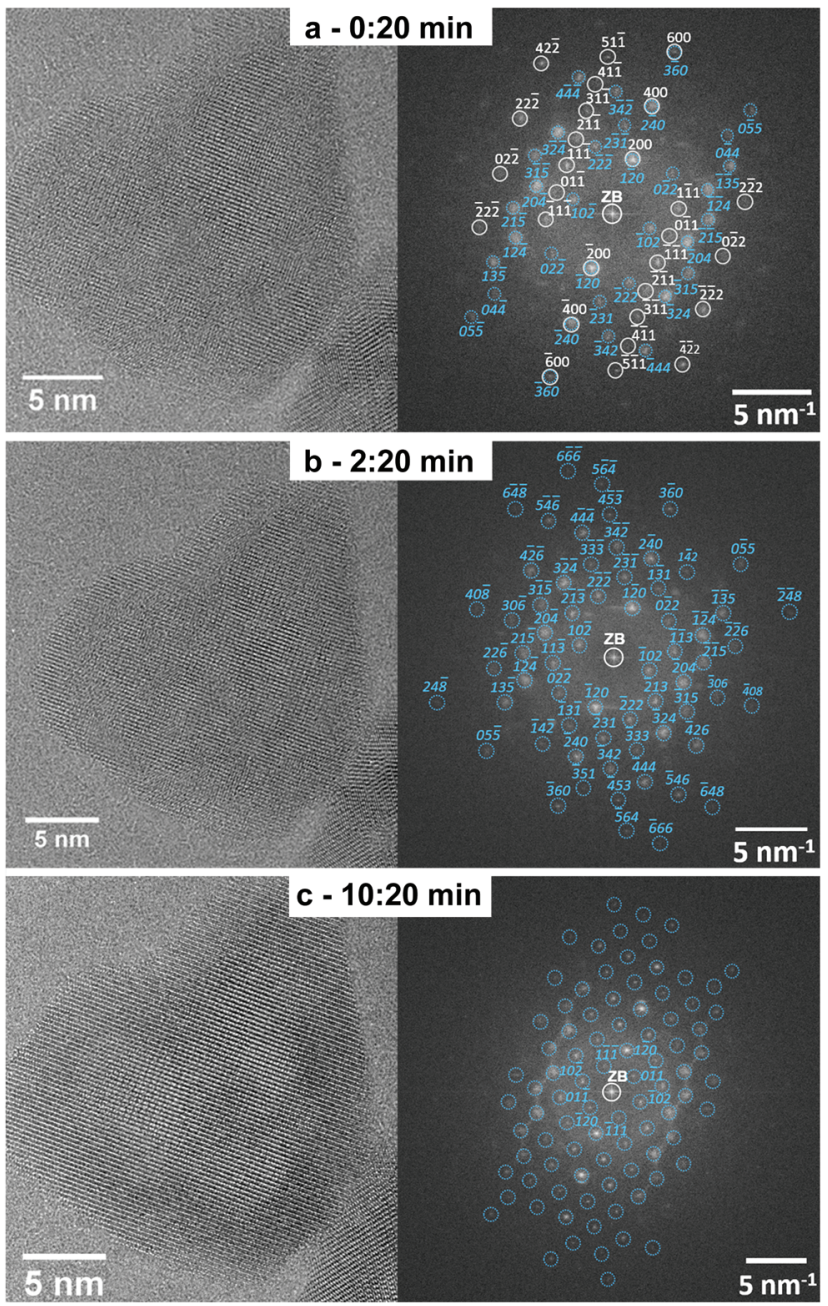

Fig. 5 Transition of a solid $\mathrm{InOOH}$ into a rh- $\operatorname{In}_{2} \mathrm{O}_{3}$ hollow particle upon electron beam irradiation: (a) HRTEM micrograph of the $\mathrm{InOOH}$ particle after 20 s illumination and its FT showing that the particle is a mixture of the orthorhombic InOOH and rh- $\mathrm{In}_{2} \mathrm{O}_{3}$ mono-crystalline phases. The FT of the HRTEM image agrees with the calculated diffraction patterns of orthorhombic $\mathrm{InOOH}$ in the [011]-zone axis (gray symbols and Miller indices) and $r h-\ln _{2} \mathrm{O}_{3}$ in the [211]-zone axis (blue circles and indices). HRTEM and FT of the nanoparticle after (b) $2 \mathrm{~min}$ and $20 \mathrm{~s}$ and (c) $10 \mathrm{~min}$ and $20 \mathrm{~s}$, when the InOOH-to-rh- $\ln _{2} \mathrm{O}_{3}$ phase transition is completed. The corresponding FTs show that the whole particle is composed of the monocrystalline $r h-\ln _{2} \mathrm{O}_{3}$ phase in the [211]-zone axis.

(HRTEM image in Fig. 5c). No further phase transformation is observed. The particle maintains the $\mathrm{rh}^{-} \mathrm{In}_{2} \mathrm{O}_{3}$ structure as demonstrated by the agreement between its FT and the calculated diffraction pattern of $\mathrm{rh}-\mathrm{In}_{2} \mathrm{O}_{3}$ in the [211]-zone axis (Fig. 5c, right panel).

The phase transformation of InOOH particles into rh- $\mathrm{In}_{2} \mathrm{O}_{3}$ hollow particles appears to start already during the short time interval of $20 \mathrm{~s}$ (corresponding electron dose $2.1 \times 10^{7} \mathrm{e} \mathrm{nm}^{-2}$ ) necessary to refocus and acquire the first HRTEM image. Phase transformation from $\mathrm{InOOH}$ into rh- $\mathrm{In}_{2} \mathrm{O}_{3}$ is completed after illumination time intervals of between $2 \mathrm{~min}$ and $20 \mathrm{~s}$ (Fig. 5b) (electron dose of $1.5 \times 10^{8} \mathrm{e} \mathrm{nm}^{-2}$ ) and $4 \mathrm{~min}$ (elec- tron dose $1.7 \times 10^{8} \mathrm{e} \mathrm{nm}^{-2}$ ) (see investigation of a nanoparticle ensemble in Fig. SI_5†). Further illumination with high-energy electrons results in an improvement of the hollow particle morphology without any further phase transformation.

We note that the phase and morphological transitions of the InOOH nanoparticles strongly depend on the electron dose. For example, a low electron dose rate of $0.89 \times$ $10^{5} \mathrm{e} \mathrm{nm}^{-2} \mathrm{~s}^{-1}$ used to record overview TEM images did not lead to any phase change after illumination time intervals of up to 2-3 min (total electron dose $1.1 \times 10^{7}-1.6 \times 10^{7} \mathrm{e} \mathrm{nm}^{-2}$ ). An increased electron dose rate of $2.5 \times 10^{5} \mathrm{e} \mathrm{nm}^{-2} \mathrm{~s}^{-1}$ successfully induces a complete $\mathrm{InOOH}-\mathrm{rh}-\mathrm{In}_{2} \mathrm{O}_{3}$ phase transition. Void formation starts, but does not lead to the complete transformation of rods into tubes even after illumination time intervals of about $25 \mathrm{~min}$ (total electron dose $3.7 \times 10^{8} \mathrm{e} \mathrm{nm}^{-2}$ ). These considerations show that the main factors, which drive the phase and morphology transformation, are the electron doses and (most likely) the electron energy that determine the average residence times of atoms on their lattice sites, besides a small local temperature increase.

Our study shows that ex situ calcination of the InOOH and Fe-doped InOOH samples in air for $30 \mathrm{~min}$ at $375^{\circ} \mathrm{C}$ and $450{ }^{\circ} \mathrm{C}$ leads to the formation of phase-pure and iron-doped metastable corundum-type $\mathrm{rh}-\mathrm{In}_{2} \mathrm{O}_{3}$ hollow particles and tubes. The same phase and morphological transformation of InOOH solid nanoparticles/nanorods into rh- $\mathrm{In}_{2} \mathrm{O}_{3}$ hollow nanoparticles/nanotubes can be induced in situ after continuous illumination with $300 \mathrm{keV}$ electrons in a transmission electron microscope for about $30 \mathrm{~min}$ and $10 \mathrm{~min}$, respectively. Estimates of the temperature increase induced by the electronbeam illumination yield values of only 10 and 12 degrees under our experimental conditions, which are much lower than the ex situ annealing temperatures. This indicates the minor role played by the temperature increase in the phase and morphological transition of nanoparticles/nanorods induced by the illumination with high-energy electrons. Hence, electron beam induced decomposition processes must be responsible for the reorganization of atoms at such a low temperature. This is supported by comparing the illumination time interval of only $20 \mathrm{~s}$ (Fig. 5 and Fig. 6), where the rh$\mathrm{In}_{2} \mathrm{O}_{3}$ crystalline phase starts to be formed, with an average residence time of $\mathrm{In}$ and $\mathrm{O}$ atoms in the $\mathrm{InOOH}$ lattice between $22 \mathrm{~s}$ and $68 \mathrm{~s}$ (see ESI $\dagger$ ) depending on the atom type and dose rate.

Electron beam induced decomposition is also expected to support water extraction despite the low temperature. The experimental electron dose rates result in an average residence time of $\mathrm{OH}$ (related to water formation and extraction) of between $51 \mathrm{~s}$ and $84 \mathrm{~s}$ (see ESI $\dagger$ ). Water extraction may be further supported under the high-vacuum conditions in the transmission electron microscope because a stronger partial pressure gradient of water is expected to enhance diffusion of water molecules.

The rapid phase and morphological transition of the InOOH nanoparticles induced by electron-beam illumination within $10 \mathrm{~min}$ as compared to $30 \mathrm{~min}$ necessary for the transition of the InOOH nanorods, can be understood by the 


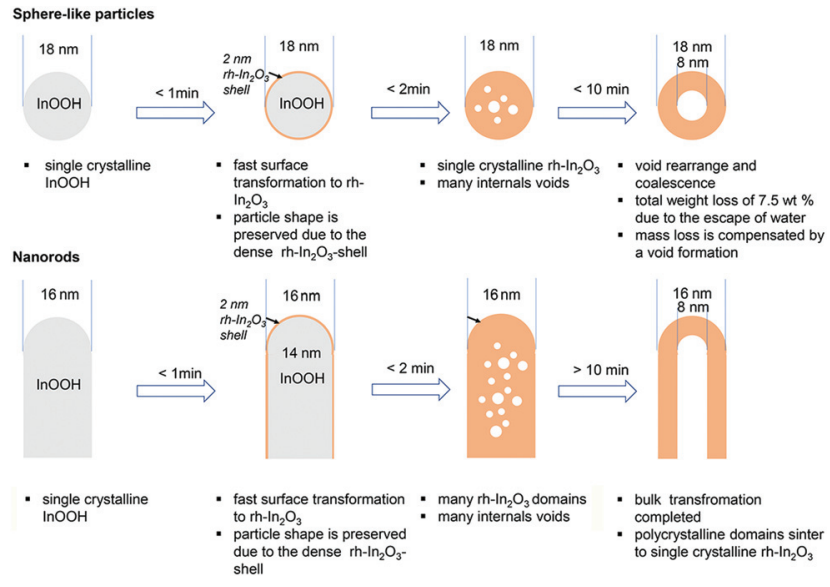

Fig. 6 Schematic illustration of the different stages of the InOOH-torh- $\mathrm{In}_{2} \mathrm{O}_{3}$ transformation.

higher electron dose rate, which results in smaller residence times of atoms on the InOOH lattice sites and by the smaller nanoparticle size compared to rods, which favors the water elimination.

Furthermore, our study provides insight also into the mechanism of the void formation in solid nanoparticles and rods that finally results in hollow nanoparticles and tubes. HRTEM characterization displays a stepwise decomposition, which develops from the particle surface and protrudes towards its core for both tubes and spherical particles. The initial formation of the rh- $\operatorname{In}_{2} \mathrm{O}_{3}$ shell at the particle surface assures the preservation of the particle morphology, shape and size, which is explained by taking into account the following features of the system under study:

(1) The InOOH-to-rh- $\operatorname{In}_{2} \mathrm{O}_{3}$ transformation goes along with densification because $\mathrm{rh}-\mathrm{In}_{2} \mathrm{O}_{3}\left(7.311 \mathrm{~g} \mathrm{~cm}^{-3}\right)$ is denser than the orthorhombic InOOH $\left(6.258 \mathrm{~g} \mathrm{~cm}^{-3}\right)$ phase. Such a densification process developing from the surface into the bulk results in the formation of a void/an empty canal in the middle of the sphere/tube because the original shape is maintained by the firstly formed $\operatorname{rh}-\operatorname{In}_{2} \mathrm{O}_{3}$ shell. Based on that, the preservation of the particle size during the InOOH-to-rh- $\mathrm{In}_{2} \mathrm{O}_{3}$ transformation can be explained.

(2) HRTEM shows that, despite a significant mass loss of about $7.5 \mathrm{wt} \%$ due to the escape of water (see Fig. 11 in ref. 21 for differential thermal analysis (DTA) of the sample under investigation), the particle size does not change during the InOOH-to-rh- $\mathrm{In}_{2} \mathrm{O}_{3}$ transformation. The mass loss is compensated by the formation of an internal void, which is understood if we consider the space required to accommodate the structural unit in each phase. Indium atoms require less space in $\mathrm{rh}-\mathrm{In}_{2} \mathrm{O}_{3}$ than in $\mathrm{InOOH}$. Indeed, in the $\mathrm{InOOH}$ structure $39.2 \AA^{3}$ per indium is available, while the rh- $-\mathrm{In}_{2} \mathrm{O}_{3}$ structure provides only $31.5 \AA^{3}$ per indium atom. When the InOOH particle transforms into the rh- $\operatorname{In}_{2} \mathrm{O}_{3}$ structure with a loss of $7.5 \mathrm{wt} \%$ due to the escape of water, the volume of the particle should decrease by a factor of $39.2 / 31.5$. The measured con- traction factors $\sqrt[3]{V_{\text {solid InOOH }} / V_{\text {hollow } \mathrm{In}_{2} \mathrm{O}_{3}}}$ of $1.031 \pm 0.033$ for the spherical particles and $1.075 \pm 0.264$ and $1.052 \pm 0.381$ for the rod-like particles of maximum and minimum length, respectively, are close to the theoretical value of 1.076. For details concerning the calculation of the contraction factors, see the ESI. $\dagger$

(3) A common feature for spheres and tubes is the development of microporosity upon dehydroxylation due to the expulsion of water. At longer irradiation times (and at higher dehydroxylation temperatures), the micropores coalesce as the result of an internal pressure of heated water vapor which is prevented from escaping the voids and their shape becomes symmetrical and uniform which is similar to previous findings. ${ }^{15}$ A significantly larger internal pressure in large crystals causes their disaggregating into small subunits/domains wherein small nanosized crystals remain intact.

As the transformed crystals retain the same size, one has to note a significant difference in the transformation mechanism attributed to the nano-Kirkendall effect typically observed in the oxidation of metallic nanoparticles (see e.g. ref. 5), in which an increased crystal size results from material (i.e. metal cation) transport outwards across the interface. In our case, a short-range migration of hydrogen atoms leads to the $\mathrm{OH}^{-}$ groups which coalesce/diffuse outwards and leave particles as water molecules. This mechanism is similar to the one previously suggested for the goethite to hematite transformation. ${ }^{13,27}$ Consequently, due to the proton transfer across the reaction interface, the matter transferred outwards is removed in the form of water, leading to void formation inside without an increase of the particle size.

\section{Conclusions}

In conclusion, the mechanisms of void formation in solid single crystalline spherical and rod-like particles during the dehydroxylation of InOOH nanoparticles into $\mathrm{rh}-\mathrm{In}_{2} \mathrm{O}_{3}$ have been evaluated comprehensively in this work. The timeresolved in situ synchrotron XRD experiments and in situ TG-DTA characterization studies show that the dehyroxylation of the InOOH spheres and the Fe-doped InOOH rods starts at $320{ }^{\circ} \mathrm{C}$ and $395{ }^{\circ} \mathrm{C}$, respectively, leading to the formation of metastable corundum-type $\mathrm{rh}-\mathrm{In}_{2} \mathrm{O}_{3}$ with a significant mass loss of about $7.5 \mathrm{wt} \%$ due to the escape of water. The ex situ HRTEM and XRD characterization studies confirmed the formation of phase-pure rh- $\mathrm{In}_{2} \mathrm{O}_{3}$ hollow spheres and iron-doped rh- $\mathrm{In}_{2} \mathrm{O}_{3}$ nanotubes by the ex situ calcination of $\mathrm{InOOH}$ and Fe-doped InOOH samples in air for $30 \mathrm{~min}$ at $375{ }^{\circ} \mathrm{C}$ and $450{ }^{\circ} \mathrm{C}$, respectively. The time-resolved high-resolution transmission electron microscopy (HRTEM) experiments reveal that electron beam induced decomposition is capable also of causing the same phase and morphology transformation. A fast InOOH to rh- $\operatorname{In}_{2} \mathrm{O}_{3}$ transformation, accompanied by the formation of several small voids within the particle/rod center due to the expulsion of water, was found to take place after a short irradiation time. At longer irradiation times, these small 
voids coalesce to form a large symmetrical and uniform hollow space/canal. The mechanism responsible for the formation of hollow rh- $\operatorname{In}_{2} \mathrm{O}_{3}$ nanoparticles from the monocrystalline InOOH nanoparticles cannot be described by the nanoKirkendall effect, but rather by mechanisms as observed in the goethite to hematite transformation: the initially formed oxide phase encapsulates the yet untransformed hydroxylated phase; consequently, the size of the obtained oxide crystals after completing the transformation retains the same size of the initial oxyhydroxide nanoparticles.

This work will allow us to understand the phenomenology and the role of electron beam induced decomposition processes on the mechanism of the decomposition of several hydroxides and oxyhydroxides such as $\mathrm{FeOOH},{ }^{15} \mathrm{AlOOH},{ }^{11}$ $\mathrm{Al}(\mathrm{OH})_{3}{ }^{12}$ and $\mathrm{In}(\mathrm{OH})_{3} \cdot{ }^{4}$ Oxyhydroxides tend to form hollow oxide structures upon decomposition (e.g. $\mathrm{Fe}_{2} \mathrm{O}_{3}, \mathrm{Al}_{2} \mathrm{O}_{3}, \mathrm{In}_{2} \mathrm{O}_{3}$ ) while a previous work in $\operatorname{In}(\mathrm{OH})_{3}$ showed that this hydroxide disintegrates into several small nanocrystallites during the decomposition. ${ }^{4}$ Since the formation of hollow structures is observed in several oxides with the corundum-type structure, questions about the structural reasons arise. This could be a topic of further - more basic - crystallographic studies. Furthermore, the careful control and optimization of electron energy, dose and dose rate, which together are responsible for electron beam induced decomposition, represents another interesting way to produce hollow nanoparticles. This method can potentially be better controlled than conventional thermal decomposition processes and could provide promising materials for several emerging applications such as energy storage and conversion and drug release.

\section{Conflicts of interest}

There are no conflicts to declare.

\section{Acknowledgements}

The authors thank the Advanced Light Source ALS (which is supported by the Director, Office of Science, Office of Basic Energy Sciences, of the U.S. Department of Energy under Contract No. DE-AC02-05CH11231), where in situ PXRD measurements were conducted at beamline 12.2.2 in the framework of AP program ALS-08865. LS appreciates the ALS for supporting his work with a doctoral fellowship. The authors thank also the KNMF (Karlsruhe Nano Micro Facility at Karlsruhe Institute of Technology, KIT) for financially supporting the TEM investigations.

\section{References}

1 L. Yu, Z. Y. Yan, Z. H. Cai, D. T. Zhang, P. Han, X. M. Cheng and Y. G. Sun, Nano Lett., 2016, 16, 65556559.
2 X. C. Ye, M. R. Jones, L. B. Frechette, Q. Chen, A. S. Powers, P. Ercius, G. Dunn, G. M. Rotskoff, S. C. Nguyen, V. P. Adiga, A. Zettl, E. Rabani, P. L. Geissler and A. P. Alivisatos, Science, 2016, 354, 874-877.

3 C. Y. Wu, W. J. Wolf, Y. Levartovsky, H. A. Bechtel, M. C. Martin, F. D. Toste and E. Gross, Nature, 2017, 541, 511-515.

4 G. Miehe, S. Lauterbach, H. J. Kleebe and A. Gurlo, J. Solid State Chem., 2013, 198, 364-370.

5 Y. Sun, X. Zuo, S. K. R. S. Sankaranarayanan, S. Peng, B. Narayanan and G. Kamath, Science, 2017, 356, 303-307.

6 X. Wang, J. Feng, Y. Bai, Q. Zhang and Y. Yin, Chem. Rev., 2016, 116, 10983-11060.

7 J. Park, T. Kwon, J. Kim, H. Jin, H. Y. Kim, B. Kim, S. H. Joo and K. Lee, Chem. Soc. Rev., 2018, 47, 8173-8202.

8 Y. Yao, F. X. Ji, M. L. Yin, X. P. Ren, Q. Ma, J. Q. Yang and S. F. Liu, ACS Appl. Mater. Interfaces, 2016, 8, 18165-18172.

9 C.-Y. Lai, B. G. Trewyn, D. M. Jeftinija, K. Jeftinija, S. Xu, S. Jeftinija and V. S. Y. Lin, J. Am. Chem. Soc., 2003, 125, 4451-4459.

10 H. Jiang, T. Wang, L. Wang, C. Sun, T. Jiang, G. Cheng and S. Wang, Microporous Mesoporous Mater., 2012, 153, 124-130.

11 H. Arami, M. Mazloumi, R. Khalifehzadeh, S. Khatiboleslam and S. K. Sadrnezhaadw, J. Am. Ceram. Soc., 2007, 90, 3311-3313.

12 Y. M. Kim, S. Lee, Y. S. Kim, S. H. Oh, Y. J. Kim and J. Y. Lee, Scr. Mater., 2008, 59, 1022-1025.

13 C. J. Goss, Mineral. Mag., 1987, 51, 437-451.

14 F. Watari, P. Delavignette and S. Amelinckx, J. Solid State Chem., 1979, 29, 417-427.

15 F. Watari, P. Delavignette, J. Vanlanduyt and S. Amelinckx, J. Solid State Chem., 1983, 48, 49-64.

16 F. Watari, J. Vanlanduyt, P. Delavignette and S. Amelinckx, J. Solid State Chem., 1979, 29, 137-150.

17 D. Walter, G. Buxbaum and W. Laqua, J. Therm. Anal. Calorim., 2001, 63, 733-748.

18 F. Caruso, R. A. Caruso and H. Mohwald, Science, 1998, 282, 1111-1114.

19 X. W. Lou, L. A. Archer and Z. C. Yang, Adv. Mater., 2008, 20, 3987-4019.

20 X. J. Wang, J. Feng, Y. C. Bai, Q. Zhang and Y. D. Yin, Chem. Rev., 2016, 116, 10983-11060.

21 L. Schlicker, M. F. Bekheet and A. Gurlo, Z. Kristallogr. Cryst. Mater., 2017, 232, 129-140.

22 A. Doran, L. Schlicker, C. M. Beavers, S. Bhat, M. F. Bekheet and A. Gurlo, Rev. Sci. Instrum., 2017, 88, 013903.

23 R. D. Shannon, Acta Crystallogr., Sect. A: Cryst. Phys., Diffr., Theor. Gen. Crystallogr., 1976, 32, 751-767.

24 M. S. Lehmann, F. K. Larsen, F. R. Poulsen, A. N. Christen and S. E. Rasmusse, Acta Chem. Scand., 1970, 24, 1662-1670.

25 N. C. Popa and D. Balzar, J. Appl. Crystallogr., 2002, 35, 338-346.

26 C. T. Prewitt, R. D. Shannon, D. B. Rogers and A. W. Sleight, Inorg. Chem., 1969, 8, 1985-1993.

27 W. J. Zhang, C. F. Huo, G. Feng, Y. W. Li, J. G. Wang and H. J. Jiao, J. Mol. Struct.: THEOCHEM, 2010, 950, 20-26. 